\title{
The Accuracy of Transcranial Doppler in the Diagnosis of Middle Cerebral Artery Stenosis
}

\author{
Jose C. Navarro ${ }^{a}$ Annabelle Y. Lao ${ }^{a, b}$ Vijay K. Sharma ${ }^{b, c}$ Georgios Tsivgoulis $^{\text {b, }}$ \\ Andrei V. Alexandrov ${ }^{b}$ \\ ${ }^{\mathrm{a}}$ Department of Neurology and Psychiatry, University of Santo Tomas Hospital, Manila, Philippines; ${ }^{\mathrm{b}}$ Department of \\ Neurology, Barrow Neurological Institute, St. Joseph Hospital, Phoenix, Ariz., USA; ' Division of Neurology, National \\ University Hospital, Singapore, Singapore; ${ }^{\mathrm{d}}$ Department of Neurology, University of Athens School of Medicine, \\ Eginition Hospital, Athens, Greece
}

\section{Key Words}

Middle cerebral artery stenosis $\cdot$ Mean flow velocity .

Positive predictive value

\begin{abstract}
Background and Purpose: It was the aim of this study to systematically review available literature on the accuracy of transcranial Doppler (TCD) compared with angiography for the diagnosis of $\geq 50 \%$ middle cerebral artery stenosis in patients with transient ischemic attack or ischemic stroke. Methods: We performed a systematic review that included original articles published on TCD accuracy from 1982 until the end of December 2005 using angiography as the gold standard. The following measures of diagnostic accuracy were obtained from each primary study: sensitivity, specificity, positive predictive value (PPV) and negative predictive value (NPV). Weighted mean averages were then calculated from individual results for different velocity cutoffs. Results: Six papers met our selection criteria. Using laboratory-specific variable mean flow velocity cutoffs, self-reported best accuracy results yield a mean weighted average sensitivity of $92 \%$, specificity of $92 \%$, PPV of $88 \%$ and NPV of $98 \%$ for 80 $\mathrm{cm} / \mathrm{s}$ cutoff. For $100 \mathrm{~cm} / \mathrm{s}$ cutoff, the sensitivities were $100 \%$, specificity $97 \%$, PPV $88 \%$ and NPV $100 \%$. Conclusions: Al-
\end{abstract}

though limited to few reports, this analysis demonstrates fair TCD performance against angiography. Since increasing velocity cutoffs do not yield decreasing sensitivity and increasing specificity, further studies are required to determine optimal velocity values and possibly other criteria such as velocity ratios to develop a screening test with balanced performance parameters.

Copyright $\odot 2007$ S. Karger AG, Basel

\section{Introduction}

Ultrasound detection of intracranial stenosis helps to identify patients at high risk of recurrent stroke [1-5]. Detection of an arterial stenosis with spectral Doppler is based on focal velocity elevations at the point of maximum arterial narrowing [6,7]. It is assumed that higher velocities can predict a greater chance of more severe disease on angiography. This approach is well studied with the cervical internal carotid artery disease $[8,9]$ but has received less scrutiny for intracranial disease.

Numerous articles have been published dealing with the accuracy of transcranial Doppler (TCD) in the diagnosis of a stenosis of the middle cerebral artery (MCA) [10-40]. In these reports, different diagnostic criteria and

\section{KARGER}

Fax +4161306 1234 E-Mail karger@karger.ch www.karger.com
(C) 2007 S. Karger AG, Basel

$1015-9770 / 07 / 0236-0325 \$ 23.50 / 0$

Accessible online at:

www.karger.com/ced
Annabelle Y. Lao, MD

Department of Neurology and Psychiatry

University of Santo Tomas Hospital

Espana, Manila 8000 (Philippines)

Tel./Fax +632712 9510, E-Mail aylmd@yahoo.com 
Table 1. Summary of published diagnostic criteria for the MCA stenosis and validation methods

\begin{tabular}{|c|c|c|}
\hline First author & Criteria & Validation imaging methods \\
\hline de Bray et al. [10] & $\begin{array}{l}\text { peak systolic frequency }>3 \mathrm{kHz} 20 \% \text { seg- } \\
\text { mental increase in peak systolic frequency }\end{array}$ & intra-arterial angiography \\
\hline Zanette et al. [11] & side-to-side asymmetry of $>20 \%$ & digital subtraction angiography \\
\hline Ley-Pozo and Ringelstein [12] & $\mathrm{MFV} \geq 80 \mathrm{~cm} / \mathrm{s}$ & digital subtraction angiography \\
\hline Carmelingo et al. [13] & $\mathrm{MFV} \geq 80 \mathrm{~cm} / \mathrm{s}$ & digital subtraction angiography \\
\hline Rorick et al. [14] & $\mathrm{MFV} \geq 80 \mathrm{~cm} / \mathrm{s}$ & digital subtraction angiography \\
\hline Gao et al. [15] & peak systolic velocity $>140 \mathrm{~cm} / \mathrm{s}$ & magnetic resonance angiography \\
\hline Sumanwela et al. [16] & $\begin{array}{l}\text { MFV }>80 \mathrm{~cm} / \mathrm{s} \text { peak systolic velocity } \\
>140 \mathrm{~cm} / \mathrm{s}\end{array}$ & $\begin{array}{l}\text { computed tomography } \\
\text { angiography }\end{array}$ \\
\hline Felberg et al. [17] & $\begin{array}{l}\text { MFV } \geq 100 \mathrm{~cm} / \mathrm{s} \text { prestenotic to stenotic } \\
\text { MCA velocity ratio of } 1: \geq 2\end{array}$ & digital subtraction angiography \\
\hline Bang et al. [18] & $\mathrm{MFV} \geq 80 \mathrm{~cm} / \mathrm{s}$ & digital subtraction angiography \\
\hline Bang et al. [19] & $\mathrm{MFV} \geq 80 \mathrm{~cm} / \mathrm{s}$ & digital subtraction angiography \\
\hline
\end{tabular}

velocity thresholds for the MCA stenosis yielded variable sensitivity and specificity parameters. Furthermore, a recent multicenter clinical study of TCD and magnetic resonance angiography (MRA) to identify $\geq 50 \%$ intracranial stenosis showed positive predictive values (PPVs) of noninvasive testing below the expected PPVs of $55 \%$ for TCD and $66 \%$ for MRA [41]. To date, no consensus is available regarding a reliable velocity threshold for MCA stenosis.

Therefore, the aim of this paper was to systematically review available literature on the subject of accuracy of TCD compared with angiography for the diagnosis of MCA stenosis. We thought to obtain test performance parameters that could be helpful to attain reliable velocity criteria for MCA stenosis.

\section{Subjects and Methods}

\section{Study Selection Criteria}

We first screened all original articles published since the first TCD paper in 1982 [20] until the end of December 2005 that reported a comparison of TCD with any cerebral angiography as the reference imaging standard. To be eligible, the report had to include TCD comparison with angiography as the gold standard, specified percent stenosis measurement and to provide details of patient populations studied. Patient populations eligible for the analysis were adults (18 years or older) of both genders with a history of stroke or transient ischemic attack. The eligible articles had to report TCD sensitivity, specificity, PPV and negative predictive value (NPV) or the likelihood ratios, or present the raw data suitable for recalculation of these values.

\section{Retrieval of the Relevant Literature}

Electronic searches were carried out using Medline, Embase, Cinahl and Cochrane Library from 1982 to 2005 applying the following key words: MCA stenosis, MCA infarction, transcranial Doppler, cerebral angiography, diagnostic test, gold standard, sensitivity, specificity, positive predictive value, negative predictive value, receiver operator characteristic (ROC) curve and likelihood ratio. Only articles written in English were included in this study. Two authors (V.K.S. and A.Y.L.) screened all retrieved articles. We first summarized all published different diagnostic criteria in original studies that also report the criteria performance against any angiographic studies (table 1). This information was used to derive the mean flow velocity (MFV) thresholds for subsequent systematic review. We then reviewed all papers for eligibility, and the reasons why certain papers did not meet the inclusion criteria are listed in table 2. Although TCD also screens for intracranial stenosis, only published articles on TCD will be included in this review for homogeneity.

\section{Extraction and Display of Data}

Two authors (J.C.N. and A.V.A.) blinded to the authorship and study institutions independently reviewed eligible articles and scored them using the 8-point validity score for methodological quality (table 3 ). For each fulfilled criterion, 1 point was given. If the criterion was not fulfilled or the answer was unclear, a score of 0 was given. Disagreements were resolved by discussion with other coauthors to arrive at a consensus assessment.

\section{Statistical Analysis}

The following measures of diagnostic accuracy were obtained from each primary study: sensitivity, specificity, PPV and NPV. First, we summarized self-reported highest test performance parameters in each selected study and calculated the mean average values of the 'best case scenario' TCD performance regardless of the laboratory-specific velocity cutoffs. We then identified sensitivity, specificity, PPV and NPV for different MCA MFV cutoffs 
Table 2. Reasons for exclusion of retrieved articles from meta-analysis

\begin{tabular}{ll}
\hline Reason & Articles excluded \\
\hline $\begin{array}{l}\text { Use of transcranial duplex imaging technologies } \\
\text { No angiography done or no use of angiography } \\
\text { as reference standard }\end{array}$ & 6 articles [20-26] \\
$\begin{array}{l}\text { Did not use } 2 \times 2 \text { table of sensitivity and specificity, or } \\
\text { results cannot be derived from the data }\end{array}$ & 14 articles [15, 16, 27-37] \\
$\begin{array}{l}\text { Total number rejected } \\
\text { Total number eligible for the analysis }\end{array}$ & $\begin{array}{l}4 \text { articles [38-41] } \\
25 \text { articles } \\
6 \text { articles [12-14, 17-19] }\end{array}$ \\
\hline
\end{tabular}

Table 3. Validity score for diagnostic test in selected papers

\begin{tabular}{|c|c|c|c|c|c|c|c|c|}
\hline Reference & $\begin{array}{l}\text { Study design } \\
\begin{array}{l}1=\text { comparative } \\
0=\text { noncomparative }\end{array}\end{array}$ & $\begin{array}{l}\text { Patient } \\
\text { selection } \\
1=\text { consecutive } \\
0=\text { nonconsecutive }\end{array}$ & $\begin{array}{l}\text { Data } \\
\text { collection } \\
1=\text { prospective } \\
0=\text { retrospective }\end{array}$ & $\begin{array}{l}\text { Observer } \\
\text { blinding } \\
1=\text { blind } \\
0=\text { nonblind }\end{array}$ & $\begin{array}{l}\text { Details on } \\
\text { both tests } \\
1=\text { sufficient } \\
0=\text { insufficient }\end{array}$ & $\begin{array}{l}\text { Verification } \\
\text { of test } \\
1=\text { complete } \\
0=\text { partial }\end{array}$ & $\begin{array}{l}\text { Data } \\
\text { reporting } \\
1=\text { sufficient } \\
0=\text { insufficient }\end{array}$ & $\begin{array}{l}\text { Details of study } \\
\text { population } \\
1=\text { sufficient } \\
0=\text { insufficient }\end{array}$ \\
\hline \multicolumn{9}{|l|}{ Ley-Pozo and } \\
\hline Ringelstein [12] & 1 & 1 & 1 & 1 & 1 & 1 & 1 & 1 \\
\hline Carmelingo et al. [13] & 1 & 1 & 1 & 0 & 1 & 1 & 1 & 1 \\
\hline Rorick et al. [14] & 1 & 0 & 0 & 0 & 1 & 1 & 1 & 1 \\
\hline Felberg et al. [17] & 1 & 1 & 1 & 1 & 1 & 1 & 1 & 1 \\
\hline Bang et al. [18] & 1 & 1 & 0 & 1 & 1 & 1 & 1 & 1 \\
\hline Bang et al. [19] & 1 & 1 & 0 & 1 & 1 & 1 & 1 & 1 \\
\hline
\end{tabular}

Table 4. Sensitivity, specificity, PPV and NPV of different cutoff points of MCA MFV for the prediction of MCA stenosis in prospective and retrospective studies

\begin{tabular}{lllllll}
\hline $\begin{array}{l}\text { MCA MFV } \\
\text { cutoff }\end{array}$ & Studies & $\begin{array}{l}\text { MCA } \\
\text { studied }\end{array}$ & $\begin{array}{l}\text { Sensitivity } \\
\%\end{array}$ & $\begin{array}{l}\text { Specificity } \\
\%\end{array}$ & $\begin{array}{l}\text { PPV } \\
\%\end{array}$ & $\begin{array}{l}\text { NPV } \\
\%\end{array}$ \\
\hline $80 \mathrm{~cm} / \mathrm{s}$ & {$[12-14,17-19]$} & 616 & 82.9 & 85.4 & 75.8 & 90.2 \\
$90 \mathrm{~cm} / \mathrm{s}$ & {$[14]$} & 99 & 75.0 & 91.0 & 56.0 & 96.0 \\
$100 \mathrm{~cm} / \mathrm{s}$ & {$[17]$} & 113 & 100 & 97 & 88.0 & 100 \\
$120 \mathrm{~cm} / \mathrm{s}$ & {$[7]$} & 113 & 68.7 & 100 & 100 & 95.0 \\
\hline
\end{tabular}

Data are weighted average means, except MCA studied. from available datasets. When studies reported different measures of diagnostic accuracy for the same MCA MFV cutoff, the weighted average sensitivity, specificity, PPV and NPV were then calculated from individual study results. The Statistical Package for Social Science (SPSS Inc., version 10.0 for Windows) was used for statistical analyses.

\section{Results}

The literature search originally identified 30 articles, 6 out of which (3 prospective and 3 retrospective) fulfilled our criteria for systematic review [12-14, 17-19]. TC2-62 EME [12, 13], TC22, TC2000 [14], Multigon and
Multidop [17] and Transcan EME [18, 19] were used. All of these devices have a $2-\mathrm{MHz}$ nonimaging Doppler probe and no angle correction. Their emission power generally does not affect velocity measurement.

The highest accuracy parameters for the different MFV cutoffs $(80,90$ and $100 \mathrm{~cm} / \mathrm{s})$ used in the former studies are presented in table 4 , together with the weighted average means for combined sensitivities, specificities, PPV and NPV for different MFV cutoffs.

When only prospective studies that evaluated patients in a consecutive fashion were analyzed, the weighted average mean accuracy parameters were higher as compared with the analysis of all the studies combined to- 
Table 5. Sensitivity, specificity, PPV and NPV of different cutoff points of MCA MFV for the prediction of MCA stenosis in prospective studies

\begin{tabular}{rllllll}
\hline $\begin{array}{l}\text { MCA MFV } \\
\text { cutoff }\end{array}$ & Studies & $\begin{array}{l}\text { MCA } \\
\text { studied }\end{array}$ & $\begin{array}{l}\text { Sensitivity } \\
\%\end{array}$ & $\begin{array}{l}\text { Specificity } \\
\%\end{array}$ & $\begin{array}{l}\text { PPV } \\
\%\end{array}$ & $\begin{array}{l}\text { NPV } \\
\%\end{array}$ \\
\hline $80 \mathrm{~cm} / \mathrm{s}$ & {$[12-14]$} & 315 & 91.8 & 92.2 & 88.8 & 98.4 \\
$100 \mathrm{~cm} / \mathrm{s}$ & {$[14]$} & 113 & 100 & 97 & 88.0 & 100 \\
\hline
\end{tabular}

Data are weighted average means, except MCA studied. gether (sensitivity 91.8 vs. $82.9 \%$, specificity 92.2 vs. $85.4 \%$, PPV 88 vs. $75.8 \%$, and NPV 98.4 vs. $90.2 \%$ ) as shown in table 5 . The former analyses indicate that the validity of TCD seems to improve when evaluated in a prospective setting.

Among the different velocity criteria, $100 \mathrm{~cm} / \mathrm{s}$ have shown the most balanced accuracy parameters with a sensitivity of $100 \%$, specificity of $97 \%$, PPV of $88 \%$ and NPV of $100 \%$.

\section{Discussion}

Our study showed variable accuracy parameters with increasing MFV for a significant ( $\geq 50 \%$ ) MCA stenosis. Average TCD performance parameters were found to be below the best results reported in individual studies. Our analysis also showed that only one MFV cutoff was evaluated in several studies. Using only the highest quality papers, it was noted that the accuracy parameters increased, which are more reflective of the previously published data regarding TCD accuracy.

Findings in the multicenter Stroke Outcomes and Neuroimaging of Intracranial Atherosclerosis and Warfarin Aspirin Symptomatic Intracranial Disease (SONIA-WASID) study showed a PPV of only 55\% [41], which was lower than the target value expected for the SONIA trials and reported in other studies. Our study showed that the expected average TCD performance based on previously published series can have a PPV of $76 \%$. Factors responsible for this incongruence are likely to be (but not limited to) the following. First, most of the subjects enrolled in the SONIA study were Caucasians who have less preponderance of intracranial disease. Second, a verification bias could play a role since angiography was not done in patients with normal TCD results. Finally, a single MFV cutoff may not take into account systemic hemodynamics or collaterals that can increase the number of false-positive TCD results.
Suboptimal TCD performance against angiography is unsettling, and besides being attributable to operator dependency of TCD, it also raises questions as to the validity of a single or dual projection digital subtraction angiography (DSA) in identifying mild and moderate intracranial disease. Our findings and those of the SONIA study may also mean that either the gold standard of invasive angiography poorly reflects the nature of intracranial disease, or current TCD velocity criteria are too simplistic and should be further refined against multiplanar DSA.

The obvious limitation of this meta-analysis is too few eligible reports that include a comparison with DSA, as well as relatively limited numbers of patients in each report. Given the publication bias towards the best results, our findings should be interpreted with caution; yet, they show deficiencies in current data on TCD performance and stress the need of further validation studies of various velocity parameters and ratios.

Among these other parameters, the peak systolic velocity has been validated using MRA in only one study [15]. Interestingly, elevated peak systolic velocity ( $>140$ $\mathrm{cm} / \mathrm{s}$ ) was an independent prognostic factor in predicting the risk of recurrent cerebral ischemic events [42]. In another study, Arenillas et al. [3] used MFV to predict the risk of recurrent ischemic events. The values for the MFV cutoffs were mild $(80-120 \mathrm{~cm} / \mathrm{s})$, moderate $(120-140$ $\mathrm{cm} / \mathrm{s})$ and severe $(>140 \mathrm{~cm} / \mathrm{s})$. Patients with MFV $\geq 120$ $\mathrm{cm} / \mathrm{s} \mathrm{had} \mathrm{more} \mathrm{clinical} \mathrm{events} \mathrm{in} \mathrm{this} \mathrm{study.} \mathrm{In} \mathrm{the} \mathrm{future,}$ it would be important to determine the severity of intracranial disease these velocities represent on angiography. One way to compensate for velocity changes due to hemodynamic factors is to deploy velocity ratios in a similar way as proposed in carotid testing [9] and grading cerebral vasospasm $[43,44]$. So far, only one paper has deployed the affected:nonaffected MCA ratio of $\geq 2$ to support velocity findings [17]. Previously suggested asymmetry indexes may also prove helpful in future studies $[11,33]$.

From published reports, it is not yet possible to conclude that higher velocity thresholds yield lower sensitiv- 
ity and higher specificity as they do in the cervical carotid testing [8]. Second, the most commonly reported cutoff of $80 \mathrm{~cm} / \mathrm{s}$ may yield fair results compared with best reported series. Further studies are required to determine the velocity threshold and other criteria (i.e. ratios) that could help develop a screening test with balanced performance parameters appropriate to patient populations.

\section{Acknowledgements}

A.Y.L., MD, received a scholarship grant from the Tan Yan Kee foundation, Philippines. V.K.S., MD, received a financial grant and fellowship from the National Healthcare Group and National University Hospital, Singapore. G.T. received a financial grant and fellowship from the Neurology Department of Eginition Hospital, University of Athens, Greece. The authors would like to acknowledged Michael D. Hill, MD, for his guidance and statistical input.

\section{References}

1 Wong KS, Li Chan YL, Ahuja A, Lam WW, Wong A, Kay R: Use of transcranial Doppler ultrasound to predict outcome in patients with intracranial large artery occlusive disease. Stroke 2000;31:2641-2647.

-2 Schwarze JJ, Babikian VL, DeWitt LD: Longitudinal monitoring of intracranial arterial stenosis with transcranial Doppler ultrasonography. J Neuroimaging 1994;4:182-187.

3 Arenillas JF, Molina CA, Montaner J: Progression and clinical recurrence of symptomatic middle cerebral artery stenosis: a long-term follow-up transcranial Doppler ultrasound study. Stroke 2001;32:28982904.

- 4 Wong KS, Li H, Lam WWM, Chan YL, Kay R: Progression of middle cerebral artery occlusive disease and its relationship with further vascular events after stroke. Stroke 2002;33:532-536.

5 Toni D, Fiorellu M, Zanette EM: Early spontaneous improvement and deterioration of ischemic stroke patients. Stroke 1998;29: 1144-1148.

6 Spencer MP, Reid IM: Quantitation of carotid stenosis with continuous wave (C-W) Doppler ultrasound. Stroke 1979;10:793798.

7 Von Reuten GM, Arnolds BJ: Transcranial Doppler sonography in cerebrovascular disease. Stroke 1985;16:A16.

-8 Grant EG, Benson CB, Moneta GL, Alexandrov AV, Baker JD, Bluth EI, Carroll BA, Eliasziw M, Gocke J, Hertzberg BS, Katarick S, Needleman L, Pellerito J, Polak JF, Rholl KS, Wooster DL, Zierler E; Society of Radiologists in Ultrasound: Carotid artery stenosis: grayscale and Doppler ultrasound diagnosis - Society of Radiologists in Ultrasound consensus conference. Ultrasound Q 2003; 19:190-198.

-9 Heijenbrok-Kal MH, Nederkoorn PJ, Buskens E, Van der Graaf Y, Hunink MG: Diagnostic performance of duplex ultrasound in patients suspected of carotid artery disease: the ipsilateral versus contralateral artery. Stroke 2005;36:2105-2109.
0 de Bray JM, Joseph PA, Jeanvopine H, Maugin D, Dauzat M, Plassard F: Transcranial Doppler evaluation of the middle cerebral artery stenosis. J Ultrasound Med 1988;7: 611-616.

11 Zanette EM, Feischi C, Bozzao L: Comparison of cerebral angiography and transcranial Doppler sonography in acute stroke. Stroke 1989;20:899-903.

12 Ley-Pozo J, Ringelstein EB: Noninvasive detection of occlusive disease of the carotid siphon and middle cerebral artery. Ann Neurol 1990;28:640-647.

13 Carmelingo M, Castro L, Censori B: Comparison of cerebral angiography and transcranial Doppler sonography in acute stroke. Acta Neurol Scand 1993;88:108-111.

14 Rorick MB, Nichols FT, Adams RJ: Transcranial Doppler correlation with angiography in detection of intracranial stenosis. Stroke 1994;25:1931-1934.

15 Gao S, Lam WW, Chan YL, Liu JY, Wong KS: Optimal values of flow velocity on transcranial Doppler in grading middle cerebral artery stenosis in comparison with magnetic resonance angiography. J Neuroimaging 2002;12:213-218.

-16 Suwanwela NC, Phanthumchinda K, Suwanwela N: Transcranial Doppler sonography and CT angiography in patients with atherothrombotic middle cererbal artery stroke. AJNR Am J Neuroradiol 2002;23:13521355.

17 Felberg RA, Christou I, Demchuck AM, Malkoff M, Alexandrov AV: Screening for intracranial stenosis with transcranial Doppler: the accuracy of mean flow velocity thresholds. J Neuroimaging 2002;12:1-6.

18 Bang OY, Cho JH, Han BI, Joo IS, Kim DI, Huh K: Transcranial Doppler findings in middle cerebral occlusive disease in relation to degree of stenosis and presence of concomitant stenosis. J Clin Ultrasound 2003; 31:142-151.

19 Bang OY, Joo IS, Huh K, Kim SY: The role of transcranial Doppler in symptomatic striatocapsular small deep infarction. J Neuroimaging 2003;13:48-52.
20 Baumgartner RW, Mattle HP, Schroth G: Assessment of $>50$ and $<50 \%$ intracranial stenoses by transcranial color-coded duplex sonography. Stroke 1999;30:87-92.

21 Griewing B, Schminke U, Motsch L, Brassel F, Kessler C: Transcranial Duplex sonography of middle cerebral artery stenosis: a comparison of colour-coding techniques frequency- or power-based Doppler and contrast enhancement. Neuroradiology 1998;4:490-495.

22 Gahn G, Gerber J, Hallmeyer S, Reichmann H, Von Kummewr R: Noninvasive assessment of the circle of Willis in cerebral ischemia: the potential of CT angiography and contrast enhanced transcranial color coded duplex sonography. Cerebrovasc Dis 1999;9: 290-294.

23 Tang SC, Jeng JS, Yip PK, Hwang BS, Lin WH, Liu HM: Transcranial color coded sonography for the detection of middle cerebral artery stenosis. J Ultrasound Med 2005; 24:451-457.

24 Gerriets T, Goertler M, Stolz E, Postert T, Sliwka U, Schlachetzki F, Seidel G, Weber S, Kaps M: Feasibility and validity of transcranial duplex sonography in patients with acute stroke. J Neurol Neurosurg Psychiatry 2002;73:17-20.

-25 Klotzsch C, Popescu O, Sliwka U, Mull M, Noth J: Detection of stenoses in the anterior circulation using frequency-based transcranial color-coded sonography. Ultrasound Med Biol 2000;26:579-584.

26 Kimura K, Yasaka M, Wada K, Minematsu K, Yamaguchi T, Otsubo R: Diagnosis of middle cerebral artery stenosis by transcranial color-coded real-time sonography. AJNR Am J Neuroradiol 1998;19:18931896.

27 Aaslid R, Marwalder TM, Nornes H: Noninvasive transcranial Doppler ultrasound recording of flow velocity in basal cerebral arteries. J Neurosurg 1982;57:769-774.

28 Alexandrov AV, Bladin CF, Norris JW: Intracranial blood flow velocities in acute ischemic stroke. Stroke 1994;25:1378-1383. 
29 Kaps M, Teschendorf U, Dorndorf W: Hemodynamic studies in early stroke. J Neurol 1992;239:138-142.

-30 Vargek-Solter V: Transcranial Doppler sonography in the acute cerebral ischemic disease. Neurol Croat 1992;41:205-211.

-31 Viola S, Antonacci R, D’Annunzio S, Faricelli A, Aquilone L, Gambi D, Malatesta G: Three dimensional transcranial Doppler in acute ischemic stroke in the territory of the middle cerebral artery: clinical and CT correlation. Ital J Neurol Sci 1991;12:545-555.

$\checkmark 32$ Apokov S, Whitman GT: Hemodynamic studies in early ischemic stroke: serial transcranial Doppler and magnetic resonance angiography evaluation. Stroke 2002;33:12741279.

-33 Suwanwela NC, Suwanvela N, Phanthumchinda K: Comparison of transcranial Doppler ultrasound and computed tomography angiography in symptomatic middle cerebral artery stenosis. Australas Radiol 2000; 44:174-177.

-34 Babikian V, Sloan MA, Tegeler CH: Transcranial Doppler validation pilot study. J Neuroimaging 1993;3:242-249.
35 Leanyvari Z, Vastagh I, Fulesdi B, Szirmai I, Lengyei A, Csiba L, Bereczki D: Computed tomographic and transcranial Doppler sonographic findings in acute and subacute phases of middle cerebral artery strokes. J Clin Ultrasound 2002;30:33-37.

36 Mattle H, Grolimund P, Huber P, Sturzenegger M, Zurbrugg HR: Transcranial Doppler sonographic findings in middle cerebral artery disease. Arch Neurol 1988;45:289-295.

37 Rother J, Schwartz A, Wentz KU, Rautenberg W, Hennerici M: Middle cerebral artery stenosis: assessment by magnetic resonance angiography and transcranial Doppler ultrasound. Cerebrovasc Dis 1994;4:273-279.

38 Lindegaard KF, Bakke SJ, Aaslid R, Nornes $\mathrm{H}$ : Doppler diagnosis of intracranial artery occlusive disorders. J Neurol Neurosurg Psychiatry 1986;49:510-518.

39 Lyrer PA, Engelter S, Radu EW, Steck AJ: Cerebral infarcts related to isolated middle cerebral artery stenosis. Stroke 1997;28:10221027.

40 Jiang Y, Hu J, Gao Q: An analysis on the diagnostic value of transcranial Doppler and angiography in transient ischemic attack. J Tongji Med Univ 2001;21:100-101.

-41 Lijmer JG, Mol BW, Heisterkamp S, Bonsel GJ, Prins MH, van der Meulen JH, Bossuyt PM: Empirical evidence of design-related bias in studies of diagnostic tests. JAMA 1999;282:1061-1066.
42 Feldman E, Wilterdink JL, Kosinski A, Chimowitz MI, Smith HH, Nichols F, Rogg J, Wechsler L, Saver J, Levine S, Tegeler C, Adams R, Sloan M; for the Stroke Outcomes and Neuroimaging of Intracranial Atherosclerosis (SONIA) Trial Investigators: Stroke neuroimaging of intracranial atherosclerosis. Neurology, in press.

43 Kern R, Steinke W, Daffertshofer M, Prager $\mathrm{R}$, Hennerici M: Stroke recurrences in patients with symptomatic middle cerebral artery disease. Neurology 2005;65:859-864.

44 Lindegaard KF, Nornes H, Bakke SJ, Sorteberg W, Nakstad P: Cerebral vasospasm diagnosis by means of angiography and blood velocity measurements. Acta Neurochir 1989;100:12-24.

45 Soustiel JF, Shik V, Shreiber R, Tavor Y, Goldsher D: Basilar vasospasm diagnosis: investigation of a modified 'Lindegaard Index' based on imaging studies and blood flow velocity measurement of the basilar artery. Stroke 2002;33:72-77.

46 Hennerici M, Meairs S: Cerebrovascular Ultrasound: Theory, Practice and Future Developments. Cambridge, Cambridge University Press, 2001, p 250. 